\title{
Research on Fracture Analysis of Box Girder with Crack Damage under Combined Loads
}

\author{
Ziya Peng ${ }^{1}$, ping yang ${ }^{1}$, yuelin song ${ }^{1}$, and Kang $\mathrm{Hu}^{1}$ \\ ${ }^{1}$ Wuhan University of Technology
}

September 16, 2020

\begin{abstract}
Abstract: The paper adopts the stress intensity factor (SIF) to carry out the fracture analysis of the box girder structure under complex load cases based on the linear elastic fracture mechanics. The related factors of crack length, crack angle, and load level are investigated emphatically. And the side load as additional impact is also investigated. The effective stress intensity factor (ESIF) and crack growth angle are obtained to evaluate the fracture performance. The results show that the effect of bending and torsion loads can be considered adopting a linear superposition rule. In analysis, the bending load can mainly promote opening fracture, and the torsion load can mainly promote sliding and tearing fracture. The change of inclined crack will cause mutual evolution between the three types of SIFs. But the torsion load has not very sensitive to the crack angles. The additional side load has a great effect on the SIFs (mode-I) along the crack front to make upper surface of deck plate dangerous. It is also found that the ESIFs are very larger at small crack growth angles. These conclusions can provide a feasible way to evaluate the fatigue performance of box girder.
\end{abstract}

\section{Hosted file}

main document_Research on Fracture Analysis of Box Girder with Crack Damage under Combined Loads.docx available at https://authorea.com/users/359308/articles/481399-research-on-fractureanalysis-of-box-girder-with-crack-damage-under-combined-loads 